\title{
PRIMENA KONVOLUCIONIH NEURALNIH MREŽA KOD PREPOZNAVANJA SLIKA U OSIGURANJU
}

\section{APPLICATION OF CONVOLUTIONAL NEURAL NETWORKS IN IMAGE RECOGNITION TO INSURANCE}

\author{
Marta Repić, Nebojša Ralević, Fakultet tehničkih nauka, Novi Sad
}

\begin{abstract}
Oblast - MATEMATIKA U TEHNICI
Kratak sadržaj - Predmet istraživanja rada jeste primena prepoznavanja slika u osiguranju uz pomoć konvolucionih neuralnih mreža. Poseban akcenat je stavljen na obradu podataka $i$ razumevanje građe konvolucionih neuralnih mreža. U radu se analizira potreba uvođenja prepoznavanja slika u osiguranje, kao $i$ dobre $i$ loše strane toga.
\end{abstract}

Ključne reči: Konvolucione neuralne mreže, Prepoznavanje slika, Osiguranje, Obrada podataka.

\begin{abstract}
The research topic of the paper is application of image recognition to insurance using convolutional neural networks. Special emphasis is on data processing and understanding the architecture of convolutional neural networks. In this paper we analyze need for introducing image recognition to insurance, and also good and bad sides of that.
\end{abstract}

Keywords: Convolutional neural networks, Image recognition, Insurance, Data processing.

\section{UVOD}

Sa inovacijama u kompjuterskoj viziji mnoge industrije su se susrele sa promenama i izazovima uslovljeni novim tehnologijama kao što je na primer prepoznavanje slika [1]. Sama reč prepoznavanje slika nam govori da je reč o tehnologiji koja služi za prepoznavanje mesta, ljudi, objekata, građevina itd. Od ove nove tehnologije se očekuje da na mnogo načina utiče na industriju osiguranja.

\section{PREPOZNAVANJE SLIKA}

Ljudima ne predstavlja nikakav napor da na primer razlikuju psa ili mačku, zahvaljujući mozgu koji nam viziju čini lakom, dok je za računare veoma komplikovano da oponašaju taj proces. S'obzirom da se digitalna slika sastoji od piksela, računar sliku vidi kao numeričku reprezentaciju ovih piksela i da bi prepoznao datu sliku mora da ustanovi šablone i pravilnosti u tim podacima. Primer prepoznavanja slika sa kojim se veoma često susrećemo jeste optičko prepoznavanje karaktera odnosno skener koji može da prepozna karaktere na slici i

\section{NAPOMENA:}

Ovaj rad proistekao je iz master rada čiji mentor je bio dr Nebojša Ralević, red. prof. samim tim transformiše tekst sa slike u tekst fajl, isto tako ovo može da se primeni i na iščitavanje broja tablice sa vozila na datoj slici. Za sada se prepoznavanje slika postepeno uvodi, i koristi se na primer u potvrđivanju identiteta korisnika, proceni rizika, u analiziranju potraživanja itd. Ove promene utiču pozitivno na vitalnost osiguranja, na ponašanje klijenata, procenu rizika kao i na deljenje informacija. Sama primena tehnologije prepoznavanja slika je komplikovana dok je proces dosta sličan tradicionalnoj statističkoj analizi.

$\mathrm{Na}$ Slici 1 možemo videti jedan takav proces, koji se sastoji od pet koraka.

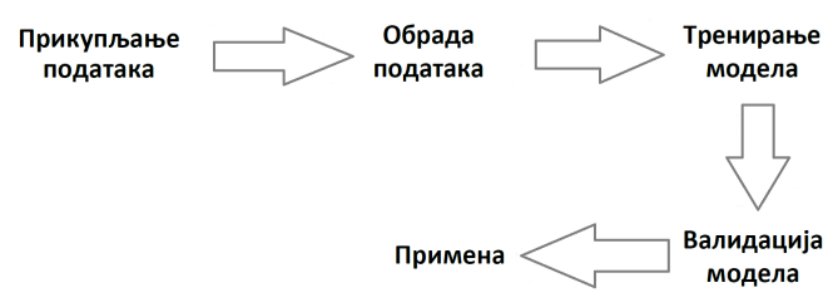

Slika 1. Proces prepoznavanja slika

[1] Pošto su slike predstavljene kao podaci, prvi korak uključuje prikupljanje tih podataka, zatim se prikupljeni podaci obrađuju (obrada se uglavnom odnosi na smanjenje njihove dimenzionalnosti), potom se model trenira da bi mogao da poveže unete podatke sa željenim izlazom (npr. kategorija ili ponašanje). Validacija modela služi da bi se potvrdilo da je model dovoljno snažan da bi mogao da predvidi izlaz. Ukoliko su rezultati zadovoljavajući, model se može koristiti u realnim problemima.

\subsection{Primena u osiguranju}

Već su predstavljene neke od primena tehnologije prepoznavanja slika u osiguranju, međutim najpre ćemo da vidimo zašto bi ova tehnologija mogla da nam bude korisna. Tajna je prvenstveno $u$ informacijama koje nam prepoznavanje slika obezbeđuje a koje ne možemo dobiti iz tradicionalnih podataka. Ukoliko imamo sliku vozača, koji vozi i istovremeno koristi mobilni telefon, to nam automatski govori da je ovo visoko - rizičan klijent. Ili na primer ukoliko nam je dostupna fotografija putanje tornada ili poplavljene oblasti, uređaji za prepoznavanje slika nam mogu pomoći u proceni stepena nastale štete kao i u lociranju ugroženih područija. Takođe bi model za prepoznavanje slika zajedno sa uslovima osiguranja trebao biti u mogućnosti da predvidi i broj potraživanja 
koja će uslediti kao i ukupnu novčanu sumu, što ustvari pomaže kompanijama da se pripreme za upravljanje potraživanjima od rizika. Međutim zašto bismo se oslonili na automatizovan sistem pre nego na ljudsku procenu? Prvenstveno zato što je nekada potrebno obraditi veliku količinu podataka u nekom vremenskom intervalu, što je za čoveka neizvodljivo. I druga stvar jeste ekonomski aspekt, dosta je isplativije koristiti model za dobijanje podataka umesto zapošljavanja neke osobe na to radno mesto.

\section{OBRADA PODATAKA}

Da bismo uopšte mogli da pričamo o funkcionisanju modela koji prepoznaje slike, prvo ćemo se pozabaviti transformacijom slike u oblik koji je lak za rad. Navešćemo par metoda koja se najčešće koriste:

Crno-bela verzija. Pošto u prepoznavanju slika boja ne igra važnu ulogu, odnosno ne utiče na razumevanje bitnih informacija sa slike, iz tog razloga je veoma česta transformacije slike u crno-beli format, a razlog za to bi bio smanjenje količine podataka koju slika sadrži. Na Slici 2 možemo videti kako je slika u boji transformisana u crnobelu i pri tome transformacija nije uticala uopšte na informaciju koja nam je bitna, a to je da vozač drži telefon u ruci.
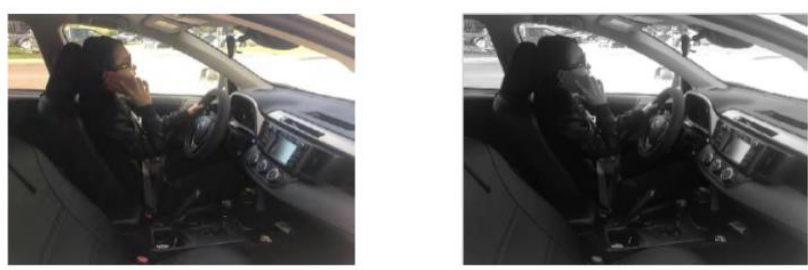

Slika 2. Transformacija slike u crno-belu [1]

Kompresija. Slika takođe može da se kompresuje na nižu rezoluciju što bi smanjilo zahteve računara i uticalo bi na "otpornost" modela na slike nižeg kvaliteta. Na Slici 3 možemo videti kompresiju slike $640 \times 480$ na 320x240 što golim okom nije vidljivo.
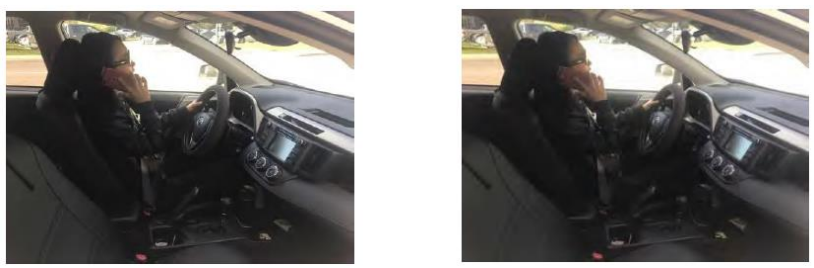

Slika 3. Kompresija slike na nižu rezoluciju [1]

Uvećanje skupa podataka. Predstavlja povećavanje količine relevantnih podataka u skupu. Neke od najčešćih tehnika za povećavanje skupa podataka su: okretanje, rotacija, skaliranje, pomeranje, sečenje i posvetljivanje [2].

Zamućenje i izoštravanje. Slike u boji kao i crno-bele mogu imati puno šumova. Da bi se šumovi otklonili koristi se zamućivanje. U oblasti obrade slike Gausova funkcija se koristi radi zamućivanja. Treba imati na umu da što je jače zamućivanje to je izoštrenost manja.

Ekstrakcija atributa. Metoda ekstrakcije atributa ima za cilj da stvori nove atribute koji sadrže istu količinu korisnih informacija, ali da tako stvoreni atributi budu $\mathrm{u}$ manje-dimenzionalnom prostoru od polaznih, zato se početni skup "sirovih podataka" ustvari izdeli u manje grupe sa kojima je posle lakše raditi.

Autoenkoderi. Autoenkoderi predstavljaju jedan relativno novi metod za smanjenje dimenzionalnosti skupa podataka. To je ustvari neuronska mreža koja je trenirana da približno kopira svoj ulaz na izlazni sloj [3]. Na Slici 4 možemo videti kako radi jedan autoenkoder.

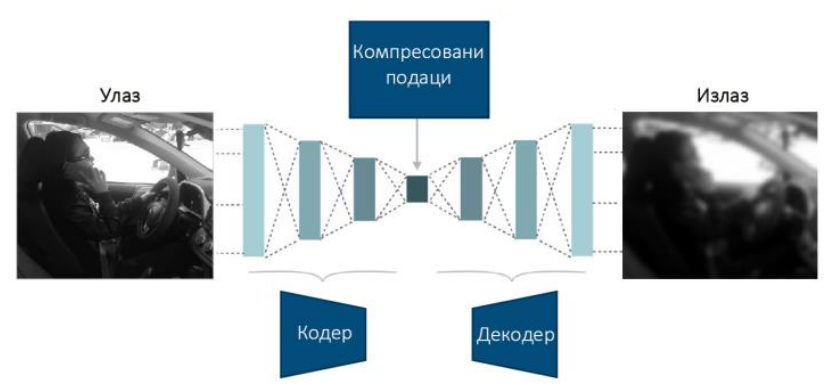

Slika 4. Princip rada autoenkodera [1]

\section{KONVOLUCIONE NEURALNE MREŽE}

Nakon uspeha $\mathrm{u}$ oponašanju nervnog sistema sa veštačkim neuralnim mrežama, ideja se proširila i na čulo vida, u smislu da se računarima obezbedi prepoznavanje slika kao što to radi ljudsko oko, tako dolazi do nastanka konvolucionih neuralnih mreža. Naziv su dobile po konvoluciji - operatoru koji se primenjuje u tehnologiji obrade slike i signala.

\subsection{Građa konvolucionih neuralnih mreža}

Sastoje se od jednog ulaznog, jednog izlaznog (potpunopovezanog) i jednog ili više skrivenih slojeva (Konvolucioni sloj, Sloj sažimanja i ReLu sloj) [4].

Ulazni sloj. To je sloj putem koga se podaci uvode $\mathrm{u}$ mrežu [5]. Ovaj sloj sadrži "sirove" vrednosti piksela slike, npr. sliku širine 32, visine 32 i dubine 3.

Konvolucioni sloj. Unutar sloja se nalaze filteri (jezgra ili detektori karakteristika) koji sadrže težine, koje je potrebno naučiti da bi mreža davala dobre rezultate. Veličina filtera je manja od veličine slike koja je ubačena u mrežu dok je dubina ista. Filteri su predstavljeni dvodimenzionalnim matricama i njihova primena na sliku se zove konvolucija što se može videti na Slici 5.

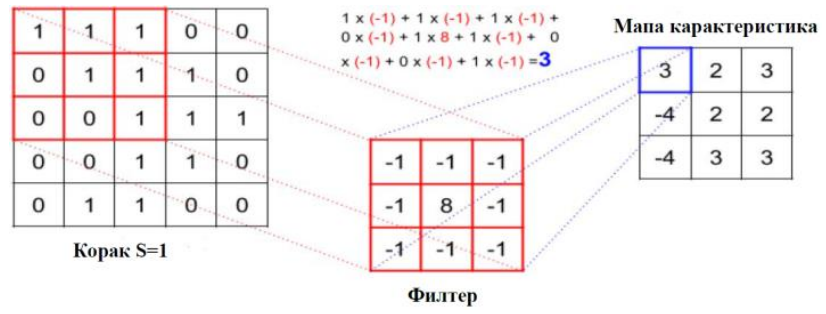

Slika 5. Konvolucija [5]

Kako je filter manje veličine nego što je slika, potrebno ga je pomerati da bismo dobili vrednosti za svaki deo slike, i to tako što krećemo iz gornjeg levog ugla i pomeramo se na desno za istu vrednost, kada dođemo do ivice pomerimo ga na dole pa opet isto ponavljamo. 
Kako svaki konvolucioni sloj može da se sastoji od više filtera to znači da će onda izlaz tih slojeva biti više dvodimenzionalnih matrica koje ćemo grupisati zajedno duž ose koja predstavlja dubinu i dobiti izlazni volumen. Kada su u pitanju ulazni podaci koji su višedimenzionalni kao npr. slika, skroz je nepraktično da se neuroni povezuju sa svim neuronima u prethodnom sloju, zato ćemo svaki neuron povezati samo sa određenom regijom ulaznog sloja. Prostorni opseg ove povezanosti je hiperparametar koji se zove receptivno polje (Slika 6) neurona odnosno veličina filtera.

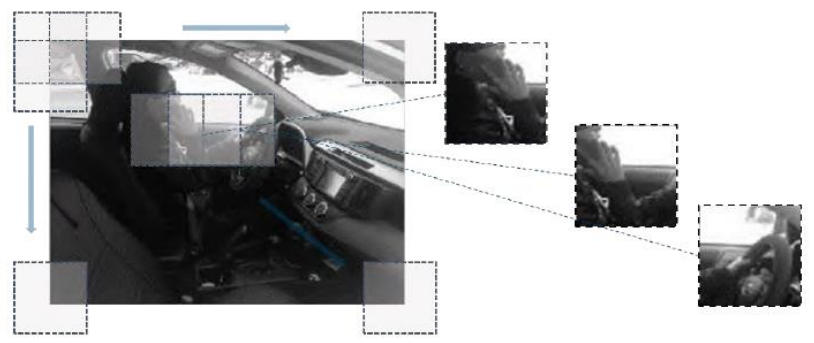

Slika 6. Receptivno polje [1]

Pitamo se da li se na ovaj način (primenom filtera) gube neke od karakteristika sa slike? Odgovor je potvrdan! Mapa karakteristika koju dobijamo na kraju ima manje ćelija pa samim tim i manje informacija. Ali to je ustvari i cilj filtera, da prođe kroz original sliku i probere informacije koje su potrebne a ostatak odbaci.

ReLu sloj. [6] Kao dodatni korak nakon konvolucije uvodi se ReLu funkcija (Slika 7). Cilj ove funkcije jeste da poveća nelineranost slike ubačene u model. Kada pogledamo u bilo koju sliku možemo videti da ona sadrži dosta nelinearnih atributa (npr. ivice, boje itd.). ReLu funkcija ustvari razbija linearnost još više da bi se nadoknadilo to što namećemo lineranost provlačenjem slike kroz konvoluciju.

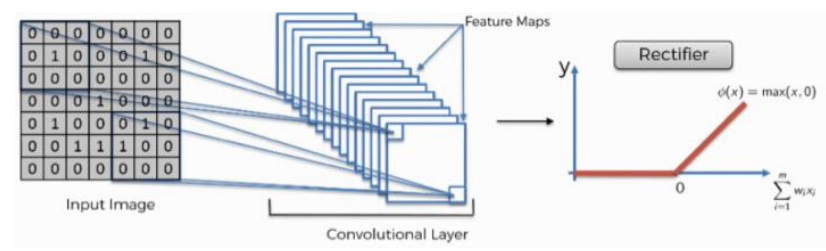

Slika 7. Receptivno polje [6]

Sloj sažimanja. Slojevi sažimanja se često koriste posle konvolucionih slojeva. I oni se sastoje od filtera ali $\mathrm{u}$ odnosu na filtere u konvolucionom sloju oni ne sadrže težine. Uloga filtera ovde jeste da na određen način izabere veličinu odnosno piksel koji se nalazi unutar njegovih dimenzija.

Najčešći način odabira jeste sažimanje maksimumom (Slika 8), odnosno bira se piksel koji ima najveću vrednost.

\section{Sažimanjem na taj način se postiže sledeće:}

1. Smanjuje se veličina slike i broj karakteristika što pojednostavljuje računanje.

2. Povećava se prostorna invarijantnost - odnosno prepoznavanje neće zavisiti od manjih translacija karakteristika unutar slike.

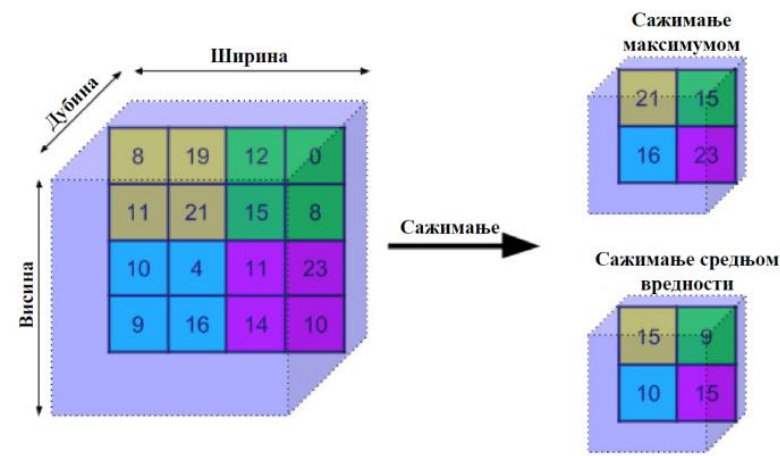

Slika 8. Sažimanje maksimumom [5]

Nakon sažimanja mape karakteristika se poravnaju u jednu kolonu (Slika 9), i time dobijamo dugačak vektor sa podacima koji predstavljaju ulaz u veštačku neuralnu mrežu.
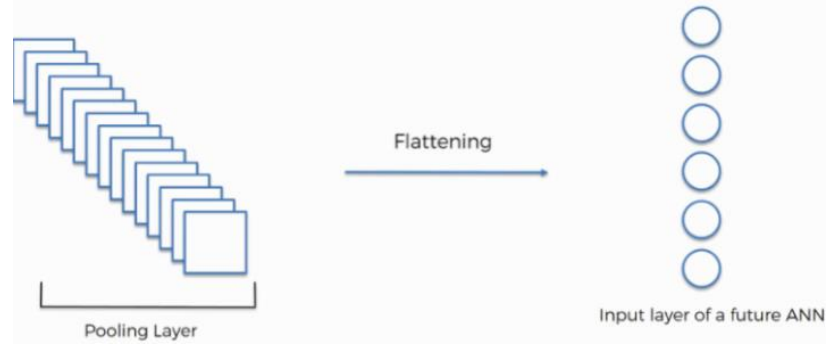

Slika 9. Poravnavanje mapa karakteristika [6]

Potpuno-povezani sloj. Kao što vidimo na Slici $\mathbf{1 0}$ poslednji korak jeste ulazak podataka u neuralnu mrežu, koja se sastoji od tri sloja: ulaznog, izlaznog i potpunopovezanog (skriveni sloj).

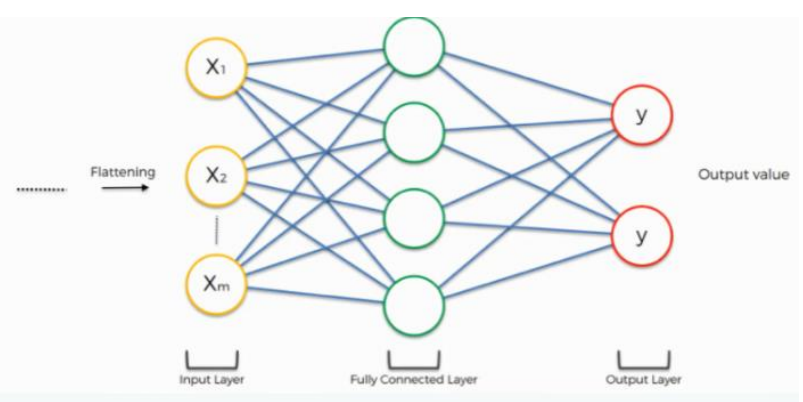

Slika 10. Veštačka neuralna mreža [6]

Ulazni sloj je vektor podataka koji smo dobili ravnanjem u prethodnom koraku.

Zadatak neuralne mreže sa Slike $\mathbf{1 0}$ jeste da uzme ulazne podatke i kombinuje karakteristike u širi spektar atributa što ustvari čini konvolucionu neuralnu mrežu još sposobnijom kod klasifikovanja slika - što je ustvari i cela svrha pravljenja ovih mreža.

Na Slici 11 možemo videti prikaz cele konvolucione neuralne mreže, koja proizilazi iz svega objašnjenog do sada. 


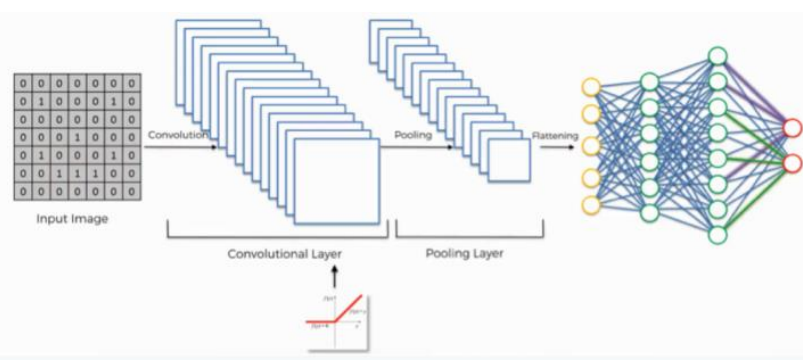

Slika 11. Konvoluciona neuralna mreža [6]

\section{PROBLEMI U PRIMENI TEHNOLOGIJE PREPOZNAVANJA SLIKA}

Pored svih nabrojanih primena treba skrenuti pažnju i na izazove odnosno probleme sa kojima se tehnike prepoznavanja slika susreću u osiguranju. Iako se preciznost tih tehnika neprekidno povećava, nekada greške ne mogu da se izbegnu. Jedan od problema bi bio ako recimo određena osoba ima svoj nalog u nekoj osiguravajućoj kompaniji i pri čemu je taj nalog zaštićen samo prepoznavanjem lika. Moglo bi da se desi da program nekog člana porodice prepozna kao korisnika i samim tim odobri pristup privatnim informacijama, tako da bi u ovim situacijama bilo dobro da se nalog zaštiti još na neki način, recimo otiskom prsta. Druga prepreka bi bila preciznost modela, jer čak i kod onih najrazvijenijih modela greška je nezaobilazna. Na Slici 12 možemo videti jedan od najčešćih primera.

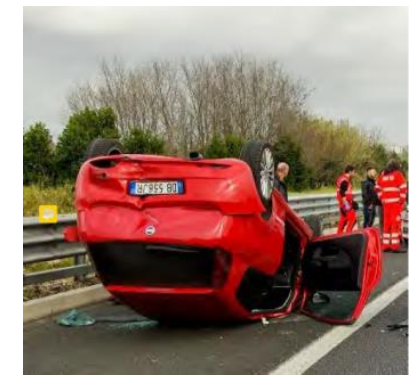

Slika 12. Prevrnut auto [1]

Najčešće se dešava da model automobil prepozna kao avion, jer se modeli uglavnom fokusiraju na oblik tela aviona (kokpit $\mathrm{i}$ trup) a zanemare ostale delove, među kojima je i rep aviona. Takođe modeli imaju problem i da naprave razliku između krila i vrata. Čak i najmanja greška modela u osiguranju bi imala znatne posledice, $\mathrm{u}$ smislu nezadovoljstva klijenta ili pak finansijski gubitak. Za sada je najbolji hibridni prilaz koji kombinuje model i čoveka, jer je ljudska inteligencija još uvek preko potrebna u slučajevima visokog rizika i onima gde model nije toliko pouzdan.

Naravno upotreba automatizovanih tehnika slikovnog prepoznavanja dovodi i do povećanja sajber rizika. Kod modela sa niskom stopom preciznosti kao i sa bliskim verovatnoćama za suprotne kategorije malverzni primeri instanca koja u sebi sadrži malu karakteristiku smetnje koja dovodi do pogrešne procene modela mogu imati veliki uticaj. Na Slici 13 možemo da vidimo do čega je dovelo dodavanje šuma slici. Iako je za ljudsko oko ovo nesmetano na procenu modela je veoma uticalo! Modeli moraju da budu istrenirani da prepoznaju ove malverzne primere i da se odbrane, jer se oni mogu nalaziti u svakoj slici koja je poslata u svrhu nekog zahteva.
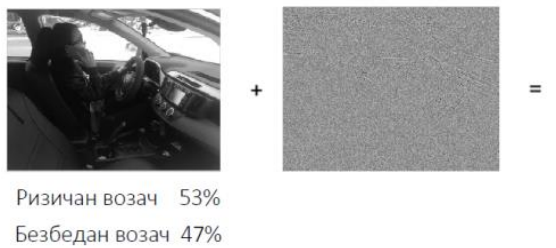

Slika 13. Dodavanje šuma slici [1]

\section{ZAKLJUČAK}

Prepoznavanje slika bi moglo da "poljulja" tradicionalne načine rada u osiguranju posebno u poslovima potraživanja, gde se jako puno vremena troši na utvrđivanje validnosti potraživanja.

Znamo da su najnapredniji algoritmi za analizu slika zasnovani na neuralnim mrežama. Sama količina podataka kojima algoritmi imaju pristup obezbeđuje da su najbolje neuralne mreže na višem nivou od ljudi u smislu dešifrovanja sadržaja sa slike.

Nova tehnologija je veoma prisutna samo je bitno efikasno je primeniti i iskoristiti u industriji.

\section{LITERATURA}

[1] Kailan Shang, FSA, CFA, PRM, SCJP "Applying Image Recognition to Insurance", Society of Actuaries Research, June 2018.

[2] https://nanonets.com/blog/data-augmentationhow-to-use-deep-learning-when-you-have-limiteddata-part-2/ (pristupljeno u oktobru 2020.)

[3] Miloš Manić “Smanjenje dimenzionalnosti prostornih podataka pomoću veštačkih neuronskih mreža", Matematički Fakultet, Univerzitet u Beogradu, 2018.

[4] https://cs231n.github.io/convolutional-networks/ (pristupljeno u septembru 2020.)

[5] Marko M. Dabović, Igor I. Tartalja“'Duboke konvolucijske neuronske mreže - koncepti i aktuelna istraživanja", Zbornik 61. Konferencije za elektroniku, telekomunikacije, računarstvo, automatiku i nuklearnu tehniku, ETRAN 2017, Kladovo, 05. do 08. juna 2017.

[6] https://www.superdatascience.com/blogs/the-ultimateguide-to-convolutional-neural-networks-cnn (pristupljeno u oktobru 2020.)

\section{Kratka biografija:}

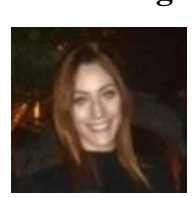

Marta Repić rođena je 29. jula 1992. godine u Novom Sadu. Završila je Gimnaziju "Jovan Jovanović Zmaj" prirodno-matematički smer, Novi Sad, 2011. godine. Diplomirala je 2017. godine na Prirodno-matematičkom fakultetu, smer Diplomirani profesor matematike. U oktobru 2017. godine upisuje master studije Matematika u tehnici na Fakultetu tehničkih nauka u Novom Sadu.

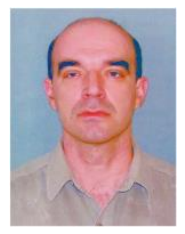

Nebojša M. Ralević rođen je 1965. god. u Beranama. Doktorirao je na PMF-u u Novom Sadu 1997. god, a od 2010. god. je u zvanju redovnog profesora matematike na FTN-u u Novom Sadu. Oblasti interesovanja su teorija mere i verovatnoće, numerička matematika, funkcionalna analiza, nelinearne jednačine, fazi sistemi, obrada slike i optimizacija. 